\title{
A knowledge, attitude and practice study on awareness and acceptance of contraception in postpartum women in a tertiary care hospital
}

\author{
Alpana Singh, Pragati Meena*, Gita Radhakrishnan, Megha Rutela
}

Department of Obstetrics and Gynecology, University College of Medical Sciences and Guru Teg Bahadur Hospital, New Delhi-110095, India

Received: 06 April 2016

Revised: 05 May 2016

Accepted: 13 May 2016

\author{
*Correspondence: \\ Dr. Pragati Meena, \\ E-mail: drpragati02@gmail.com
}

Copyright: (C) the author(s), publisher and licensee Medip Academy. This is an open-access article distributed under the terms of the Creative Commons Attribution Non-Commercial License, which permits unrestricted non-commercial use, distribution, and reproduction in any medium, provided the original work is properly cited.

\section{ABSTRACT}

Background: India was the first country in the world to launch National Family Planning Programme in 1951. This was first step taken to stabilize population, but still lag behind in limiting family size and practicing contraceptive use. 55 million unintended pregnancies occur every year in developing countries due to no contraception use. 25 million pregnancies occur due to inconsistent or incorrect use of contraception method and contraception failure. The reason for promotion of family planning services to increase inter-pregnancy interval, birth spacing or to delay conception after birth by this method we can achieve optimum maternal and child outcome. This study was conducted to assess knowledge, awareness and acceptance about contraceptive methods during postpartum period.

Methods: A prospective observational questionnaire based study in which 500 postpartum women belongs to 15 to 45 years age group was interviewed with informed verbal consent. This was KAP study regarding socio-demographic profile, awareness and acceptance of contraceptive method in postpartum period or during inter-pregnancy and factors affecting its use.

Results: Statistical analysis of univariate and bivariate data done by using chi-square test and percentage (\%). Out of 500 postpartum women, $46 \%$ women reported that they did not use any contraceptive method before. There was a significant association between contraceptive use with religion and education status $(\mathrm{p}=0.000, \mathrm{p}=0.042$ respectively). $62 \%$ obtained information from health professional (doctor/nurse), $23.8 \%$ obtained information from husband $44.4 \%$ of postpartum women implied that they would use contraceptive. Barrier method is the most preferred method $(40.1 \%)$ of contraception.

Conclusions: To improve maternal and child outcome, health professionals should be more focused to encourage effective and high quality contraceptive counseling during antenatal, intrapartum and postpartum period.

Keywords: Contraceptive method, Postpartum counseling, Pregnant women, Family planning programme

\section{INTRODUCTION}

Urological injuries which involve damage to the urinary Current population of India is 1.27 billion according to World Population Datasheet 2013, 17.64\% growth rate of India in last decade. ${ }^{1,2}$ India is the second most populous country of the world after China. ${ }^{3}$ In next few decades India will cross China if this growth rate will keep on increase by exponential growth.
Effective contraceptive use during postpartum period can prevent unintended pregnancies and help in birth spacing. Inter pregnancy interval should be more than 24 months according to WHO Guidelines 2005.,4-6 In India prevalence of contraceptive use is $73 \%$, out of which effective methods used in $46 \%$ in the age group of 15-49 years. $^{7}$

Family Planning Programme first launched by India in $1952 .^{3}$ India is the first country in the world to launch family planning programmes. Despite of this fact, India is 
still lag behind in limiting family size and practicing contraception. This was first step taken by India to stabilize population. By this programme India yielded excellent results by decreasing total fertility rate. Contraception usage in 1965-2009 increased by $48 \%$ and total fertility rate decreased by $5.7 \%$ to $2.6 \%$. $^{3}$

55 million unintended pregnancies occur every year in developing countries due to no contraception use. 25 million pregnancies occur due to inconsistent or incorrect use of contraception method and contraception failure. Maternal mortality rate would significantly decline by $25-30 \%$ by consistent and correct usage of contraceptive method by preventing unintended pregnancies. ${ }^{8}$ Evidence shows that short inter-pregnancy internal ( $<6$ months) and increases health risk to mother and newborns and increased maternal morbidity and mortality.

Recent studies shows maternal and infant survival increased by 2-5 times as high, if inter pregnancy level increases. Use of contraceptive method decrease TFR by $2.7 \%$ according to national family health survey-3 survey (2005-2006) which corresponds to contraceptive usage (56\%) among married women. ${ }^{9}$

\section{METHODS}

The present study was a hospital based prospective, observational study. A total of 500 postpartum women (postnatal or post-cesarean) were enrolled for the study and delivered in Department of Obstetrics \& Gynaecology at UCMS and GTB Hospital, Delhi, India. 500 postpartum women were interviewed after taking informed verbal consent, on the basis of prestructured questionnaire. Women were counselled regarding need of postpartum contraception according to cafeteria approach by using interpersonal communication.

\section{RESULTS}

A total of 500 eligible postpartum women were included in the study. Mean age of postpartum women was 30.5 years. Majority of them (60\%) belongs to 25-34 years. Out of them $28.6 \%$ were illiterate. Family income of majority of women $(59 \%)$ was $<1000$ and most of them (75\%) belongs to Delhi. Majority of women (73\%) had 2 living issues and most of them (85\%) were housewives. The main reasons for non-acceptance of contraceptive use were faith or religion $(47.2 \%)$ followed by desire of more children $(38.8 \%)$. Frequency of contraceptive use was highest amongst 25-34 years age group. 84.6\% women were not discussed with husband (Table 1).

Contraceptive use was significant more in 25-34 years age group compared to 15-24 years and 35-45 years age group $(\mathrm{p}=0.000)$ (Figure 1$)$.

There was significant difference in contraceptive use between religions $(\mathrm{p}=0.000)$ (Figure 2).
There was significant difference between contraceptive use and education status ( $\mathrm{p}=0.05)$ (Fig. 3).

\section{DISCUSSION}

In our study $36.6 \%$ postpartum women aware and used contraceptive method after previous delivery. 51.6\% never used any method of contraceptive. According to NFHS-3 survey $75 \%$ women used family planning method. ${ }^{9}$ Shweta et al study shows more than $90 \%$ had awareness about contraceptive method According to NFHS-3 data, contraception use prevalence rate among married women who have been used any type of contraceptive method was $55 \% .^{10,11}$

Table 1: Socio-demographic profile of study subjects.

\begin{tabular}{|c|c|c|}
\hline Demographic Profile & No. & Percentage \\
\hline \multicolumn{3}{|l|}{ Resident } \\
\hline Delhi & 375 & 75 \\
\hline Outside Delhi & 125 & 25 \\
\hline \multicolumn{3}{|l|}{ Religion } \\
\hline Hindu & 322 & 64.4 \\
\hline Muslim & 176 & 35.2 \\
\hline Others & 2 & 0.4 \\
\hline \multicolumn{3}{|l|}{ Education } \\
\hline Illiterate & 143 & 28.6 \\
\hline$<8^{\text {th }}$ standard & 213 & 42 \\
\hline 9-12 standard & 116 & 24.8 \\
\hline Graduate or above & 28 & 5.6 \\
\hline \multicolumn{3}{|l|}{ Occupation } \\
\hline Housewife & 450 & 87.5 \\
\hline Working & 50 & 12.5 \\
\hline \multicolumn{3}{|l|}{ Family income } \\
\hline$<5000$ & 106 & 21.2 \\
\hline $5000-10000$ & 285 & 57.0 \\
\hline $11000-15000$ & 76 & 15.2 \\
\hline$>15000$ & 33 & 6.6 \\
\hline \multicolumn{3}{|l|}{ Residence } \\
\hline Urban slum & 400 & 80 \\
\hline Rural & 100 & 20 \\
\hline \multicolumn{3}{|l|}{ Family size } \\
\hline$<5$ & 297 & 59.5 \\
\hline $6-10$ & 197 & 38.3 \\
\hline$>10$ & 6 & 1.2 \\
\hline \multicolumn{3}{|l|}{ Parity } \\
\hline$\leq 3$ & 365 & 73.0 \\
\hline $4-5$ & 134 & 26.8 \\
\hline$\geq 6$ & 1 & 0.2 \\
\hline \multicolumn{3}{|l|}{ Exclusive breastfeeding } \\
\hline Yes & 489 & 97.8 \\
\hline No & 11 & 2.2 \\
\hline \multicolumn{3}{|c|}{ Postpartum high fertility rate awareness } \\
\hline Yes & 300 & 60 \\
\hline No & 200 & 40 \\
\hline
\end{tabular}




\begin{tabular}{|c|c|c|}
\hline \multicolumn{3}{|c|}{ Postpartum contraceptive awareness } \\
\hline Yes & 183 & 36.6 \\
\hline No & 317 & 63.4 \\
\hline \multicolumn{3}{|l|}{ Partner discussion } \\
\hline Yes & 77 & 15.4 \\
\hline No & 423 & 84.6 \\
\hline \multicolumn{3}{|l|}{ Sexual activity } \\
\hline$<6$ week & 86 & 17.2 \\
\hline$>6$ week & 414 & 82.8 \\
\hline \multicolumn{3}{|c|}{ Interpregnancy interval $(n=400)$} \\
\hline$<3$ years & 303 & 75.75 \\
\hline 4-6 years & 80 & 20.0 \\
\hline$>7$ years & 17 & 4.25 \\
\hline \multicolumn{3}{|c|}{ Contraceptive use after previous delivery $(n=400)$} \\
\hline Yes & 150 & 37.5 \\
\hline No & 250 & 62.5 \\
\hline \multicolumn{3}{|c|}{ Contraceptive method use before } \\
\hline Condom & 202 & 40.4 \\
\hline $\mathrm{CuT}$ & 14 & 2.8 \\
\hline POP & 16 & 3.2 \\
\hline Ligation & 2 & 0.4 \\
\hline Traditional methods & 37 & 7.4 \\
\hline None & 229 & 45.8 \\
\hline \multicolumn{3}{|l|}{ ANC visit } \\
\hline Yes & 298 & 58.4 \\
\hline No & 202 & 41.6 \\
\hline \multicolumn{3}{|c|}{ Postpartum counselling during ANC visits } \\
\hline Yes & 168 & 33.6 \\
\hline No & 332 & 66.4 \\
\hline \multicolumn{3}{|l|}{ Source of information } \\
\hline Husband & 119 & 23.8 \\
\hline Doctor/Nurse & 310 & 62 \\
\hline Friend & 2 & 0.4 \\
\hline Pharmacist/Chemist & 16 & $3 \%$ \\
\hline Media & 55 & $11 \%$ \\
\hline
\end{tabular}

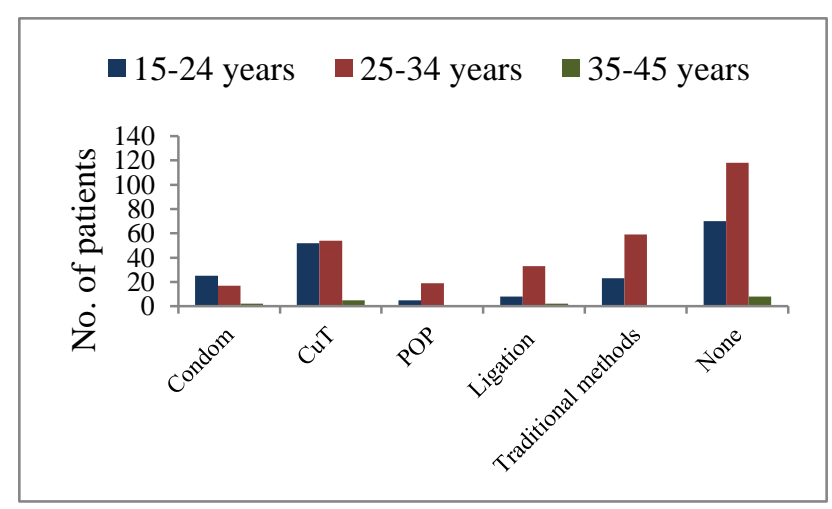

$\mathrm{P}=0.000$

Figure 1: Contraceptive use in various age groups.

In our study, $40 \%$ women preferred barrier method, $46 \%$ preferred no contraceptive method and $7.4 \%$ preferred traditional method.
According to DHS (2008-2009) prevalence of use of traditional contraceptive method was $12.7 \%$. In our study, POP use was $3.2 \%$. According to USNAID, use of injectable contraceptive was $2.7 \%$, least accepted method because it is not available in government supply.

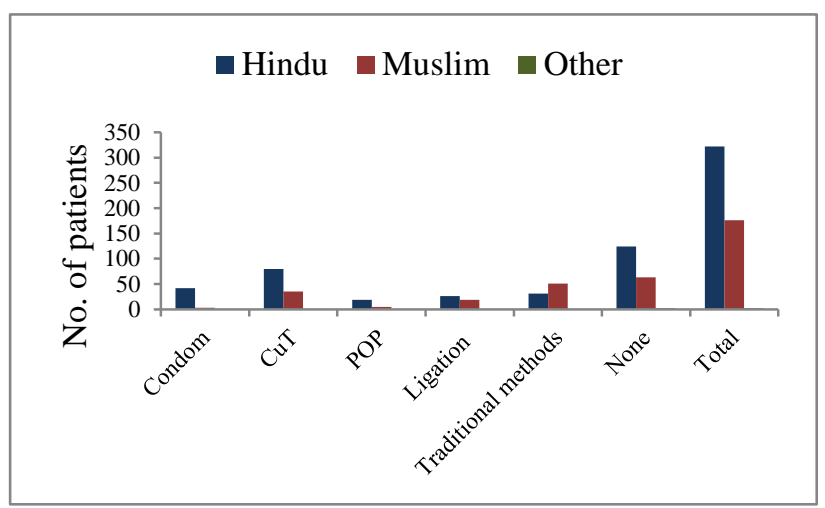

$\mathrm{P}=0.000$

Figure 2: Religion and contraceptive use.

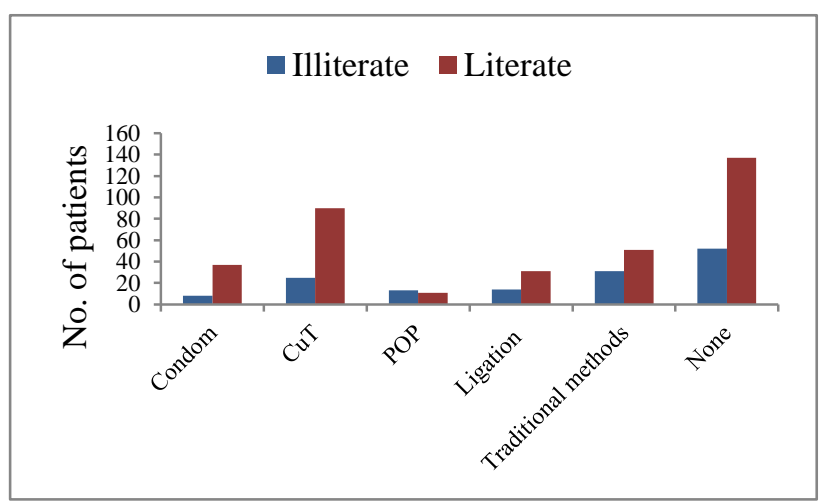

$\mathrm{P}=0.05$

Figure 3: Education and contraceptive use.

Majority of women convinced to use PPIUCD and barrier methods may be because of free government supply and better reliability, no need of daily use required. Women with $\geq 3$ living issues were counselled for terminal method like ligation either by laparoscopy or interval tubal ligation or mini-laparotomy.

Even after counselling, $46 \%$ women did not prefer to use any suggested contraceptive methods. Majority of women were rigid to not to use any contraceptive method. $7.4 \%$ women used traditional method like safe period, abstinence, coitus interrupts The main reasons for nonacceptance were religious belief or faith followed by desire for more children. $84.6 \%$ females did not discussed about contraceptive method with husband. This is reflecting less spousal communication. If spousal communication increases will probable increase use of contraceptive method.

Study done by Shweta et al $45 \%$ women discussed with partner. $^{12}$ Husband was playing important role in 
contraceptive method acceptance. Therefore there is need of counselling of couples. A study done by Rajni et al shows male dominancy is quite common in rural India, where contraception is considered wife duty toward their husbands. Now trend is changed women wanted nondependence on husband and wants contraception according to their convinence. ${ }^{13}$ By this method rapidly increasing population of India may not bring down or limit the family size but will decrease the population burden significantly or stabilize population. Media help in awareness about family planning services by using (IEC) information, education and communication campaign. $^{14,15}$

$60 \%$ women had awareness about postpartum high fertility rate. $36.6 \%$ women had awareness or positive attitude about postpartum contraceptive use. About $49 \%$ women had inter pregnancy interval of 2-3 years whereas $11 \%$ women had interval of $<1$ year between two children.

In our study $36.6 \%$ postpartum women ever used any contraceptive method and $51.6 \%$ never used any method of contraception. $58.4 \%$ women had regular ANC visit, out of them only $33.6 \%$ patients had postpartum counselling during ANC visit.

There was significant difference between contraceptive use and education status $(\mathrm{p}=0.05)$. Contraceptive use was higher in literate women. There was significant difference in contraceptive use between religions $(p=0.000)$. Contraceptive acceptance increases with age, educational status, family income. The study shows significant rise in contraceptive use after postpartum counselling $(36 \rightarrow 46 \%)$. A study done by Medina et al shows similar results $(33 \%){ }^{16}$

\section{CONCLUSION}

To improve maternal and child outcome, health professionals should be more focused to encourage effective and high quality contraceptive counselling during antenatal, intrapartum and postpartum period.

\section{Funding: No funding sources}

Conflict of interest: None declared

Ethical approval: The study was approved by the Institutional Ethics Committee

\section{REFERENCES}

1. Rutaremwa G, Kabagenyi A, Wandera SO, Jhamba T, Akior E, Nviiri HL. Predictors of modern contraceptive use during the postpartum period among BMC Public Health. 2015;15:262-70.
2. Yilmazel G, Balci E. Preferences and related factors for postpartum contraception in pregnant women. Iran J Reprod Med. 2013;11(10):801-6.

3. Population Challenges and Development Goals, Department of Economic and Social Affairs, Population Division. United Nations New York, 2005.

4. Jackson E. Controversies in postpartum contraception: When is it safe to start oral contraceptives after childbirth? Thromb Res. 2011;127:35-9.

5. Marston C. Report of a WHO technical consultation on birth spacing. WHO Press; 2005.

6. Cwiak C, Gellasch T, Zieman M. Peripartum contraceptive attitudes and practices. Contraception. 2004;70:383-6.

7. Ergoçmen B, Yigit E, Tunckanat FH. Family Planning. Turkey Demography and Health Study 2008. 1st Ed. Ankara: Hacettepe University Hospitals Printing Office Press; 2009.

8. WHO, unsafe abortion; Globally \& regional estimates of incidence of unsafe abortions and associated mortality in 2003, fifth ed. Geneva; WHO 2007.

9. National family health survey-3(NFHS-3), 2005-06, volume-1, international institute for population sciences, Deonar, Mumbai, Ministry of Health And Family Welfare, GOI.

10. Bhasin K, Pant M, Mehta M, Kumar S. Prevalence of usage of different contraceptive methods in East Delhi- a cross sectional study. Indian J Comm Med. 2005;30:52-5.

11. Kaushal SK, Saxena SC, Srivastava VK, Gupta SC, Nigam S. KAP study on contraceptive methods in Kanpur district of UP. Indian J Comm Health 2010;21:33-8.

12. Dabral S, Malik SL. Demographic study of Gujjars of Delhi: IV. KAP of family planning. J Hum Ecol. 2004;16(4):231-7.

13. Renjhen P, Gupta SD, Barua A, Jaju S, Khati B. A study of knowledge, attitude and practice among women of reproductive age group in Sikkim. J Obstet Gynaecol India. 2008;58:63-7.

14. Ddry JR, Clark LT, Chase CL, Levy M. Can mass media advertising increase contraceptive use. Fam Plann Perspect. 1972;4:37-44.

15. Wakefield MA, Loken B, Homik RC. Use of mass media campaigns to change health behaviour. Lancet. 2010;376:1261-71.

16. Mecina R, Lundgren R, Mendoza I. Strengthening of the postpartum and postabortion family planning program of the Escuela Hospital. In: Medina R, Lundgren R, Mendoza I, eds. Final Report Tegucigalpa, Honduras. Ministry of Health and INOPAL III/Population Council, August 1998.

Cite this article as: Singh $\mathrm{A}$, Meena $\mathrm{P}$,

Radhakrishnan G, Rutela M. A knowledge, attitude and practice study on awareness and acceptance of contraception in postpartum women in a tertiary care hospital. Int J Reprod Contracept Obstet Gynecol 2016;5:1921-4. 